\title{
A Monitoring System Architecture and Calculation of Practical Recycling Rate for End-of-Life Vehicle Recycling in Korea
}

\author{
Jung Whan Park', Hwa-Cho Yi', Myon Woong Park', and Young Tae Sohn² \\ 1 School of Mechanical Engineering, Yeungnam University, 214-1, Dae-dong, Gyoungsan, Gyoungbuk 712-749, South Korea \\ 2 Korea Institute of Science and Technology, Hwarangro 14-gil, Seongbuk-gu, Seoul 136-791, South Korea \\ \# Corresponding Author / E-mail: jwpark@yu.ac.kr, TEL: +82-53-810-3524, FAX: +82-53-810-4627
}

KEYWORDS: End-of-Life Vehicle, Recycling, Monitoring, Recycling Rate, Standard Recycling Rate database

\begin{abstract}
End-of-life vehicles (ELVS) are important recycling sources, and there are several recycling stages, including dismantling, shredding, and treatment of the automotive shredder residues (ASR). The legal recycling rate should be at least 95\% by 2015. To achieve this, a unified system to monitor the recycling of ELV parts and to calculate practical recycling rates is required. This paper describes a web-based monitoring system equipped with the databases for a standard parts list, dismantling \& recycling, and standard recycling rate. The system effectively collects dismantling \& recycling data, and it calculates a part's recycling rate based on the collected data. It also facilitates the estimation of a reasonable recycling rate for unreported parts by utilizing a standard recycling rate and respective ratio of treatment. The system is designed and implemented in a Windows ${ }^{\circledR}$ environment, as part of a research project sponsored by the Ministry of Environment of Korea.
\end{abstract}

Manuscript received: October 11, 2013 / Accepted: December 19, 2013 (Invited Paper)

\section{Introduction}

It is an important issue to properly recycle end-of-life vehicles (ELVs), which are composed of various kinds of materials such as ferrous and non-ferrous metals, plastics, glass, rubber, etc. Roughly $75 \%$ of an ELV by weight consists of metallic material, so ELVs should be recycled as much as possible. It was reported that on average, 670,000 waste vehicles per year were dismantled during the period of 2008 to 2010 in Korea. ${ }^{1}$

The EU (European Union) Directive $2000 / 53 / \mathrm{EC}^{2}$ as well as Commission Decision 2005/293/EC ${ }^{3}$ have imposed a basic guideline for ELV recycle monitoring and recycling rate. Regulatory requirements for the ELV recycling based on the 'Act on resources recycling of electric \& electronic equipment and vehicles' by Korea's Ministry of Environment will result in law enforcement of reasonable treatment \& recycling. ${ }^{4}$ Regulatory requirements will eventually require a $95 \%$ recycling rate, including $10 \%$ energy recovery by $2015 .{ }^{2}$ The need for a higher recycling rate is growing. Accordingly, many European and Asian countries have investigated and assessed their ELV treatment process to improve material recovery techniques such as
Italy, ${ }^{5}$ the Netherlands, ${ }^{6}$ Germany, ${ }^{7}$ Denmark, ${ }^{8}$ Japan and Taiwan..${ }^{9} 10$

Ways to satisfy the requirements of the rather high recycling rate legally as well as technologically include vehicle design for disassembly and dismantling, ${ }^{5,12}$ efficient recycling technologies to yield more material return, and EPR (extended producer responsibility) regulation. As for more material recovery, the treatment of ASR (automobile shredder residue) from which ferrous and non-ferrous metals can be recovered has steadily been studied., ${ }^{5,13-16}$

In addition, a practical and effective recycle monitoring system should be designed and implemented to check whether the dismantled parts are properly recycled, and to collect recycling data (e.g., recyclers, materials, weight, etc.) for verification of the ELV recycling. As for the recycle of waste electrical and electronic equipment, there is a reporting tool, WF-RepTool, ${ }^{17}$ that is used to track all part fractions of $\mathrm{WEEE}^{18}$ (waste electrical and electronic equipment) until their final use of final disposal, and allows to calculate recycling and recovery rates. But it is rarely found such an integrated and systematic data collecting application for the ELV recycling.

EcoAS is a network network-based official reporting system in Korea ${ }^{6}$ but it does not encompass all operators, nor does it guarantee 
completeness of the input data. In addition, dismantlers and recyclers may report only rough estimates of treatment weight. There are similar reporting systems in Taiwan and Japan, ${ }^{9,10}$ but they seem to have restricted monitoring functionalities. Therefore, a monitoring system that can collect dismantling \& recycling data and calculate recycling rates is required.

The practical recycle monitoring system is designed for (1) data maintainability, from dismantling to final treatment; (2) tracing dismantled part usage and weight data throughout the whole recycling process; and (3) practical calculation of the recycling rate of the dismantled ELVs. This research is a part of on-going R\&D projects sponsored by the Ministry of Environment, which is developing dismantling facilities and monitoring software.

Section 2 describes the current status of recycle monitoring and the need for an effective monitoring system. The system architecture and data processing are explained in the Section 3, followed by a practical strategy for recycling rate calculation.

\section{Current Status and Requirement of ELV Recycling and Monitoring}

The dismantling and recycling flow for an ELV can be summarized as follows. A waste vehicle starts the recycling process at a dismantling plant. It is required by law that the dismantler separate designated parts such as refrigerants, fuel, fluid oil, lubricants, tires, airbags, bumper covers, fuel tanks, catalysts, and batteries from the ELV. Then, reusable parts are separated to be sold and reused, and reusable core parts of a component are retreated for use as main parts of new components through remanufacturing. Other detached metallic parts are collected and sent to steel mills (ferrous metal) or smelters (non-ferrous metal) for material recycling. The vehicle shell (hulk) is then shredded, and materials are separated by proper methods, where ASR is further recycled for energy recovery and sent to a landfill. A typical dismantling and recycling process is described in Fig. $1,{ }^{20}$ and a sample recycling map after dismantling is illustrated in Fig. 2 based on a field survey in Korea.

The ELV recycling schemes are nearly invariant in countries such as Taiwan, Japan, China, Korea, the USA, and EU countries. ${ }^{9,10,21-25}$ The operators in the scheme include collectors, dismantlers, shredding plants, ASR treatment facilities, recyclers, and dealers of reused and secondary products. ${ }^{9}$ From a monitoring point of view, the ideal

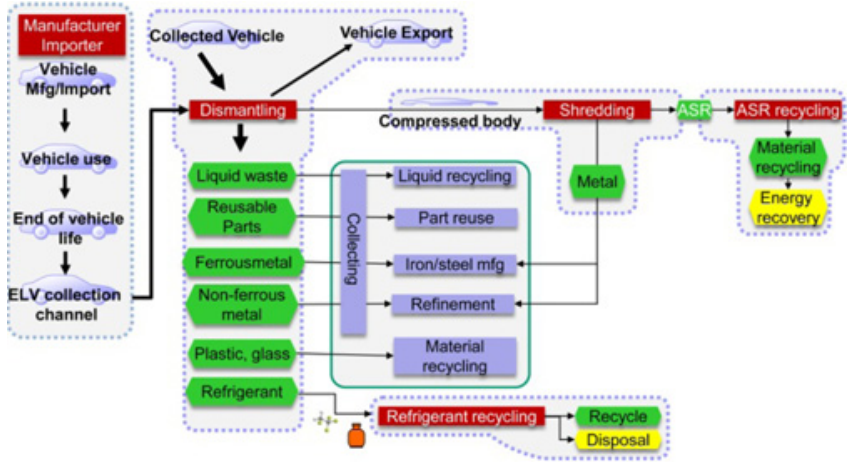

Fig. 1 Typical ELV recycling process situation involves all operators reporting treatment results (e.g., materials and weight data) regularly and faithfully, but this is difficult to expect due to practical issues. Firstly, it poses a problem of complicated material flow (see Fig. 3) because many operators are involved in the overall recycling process. Secondly, not all operators faithfully report their treatment results, partly because a proper reporting \& monitoring system is not available. Therefore, either inexact recycling data would be gathered, or recycling data would be missed.

The Ministry of Environment constructed an official reporting system called EcoAS, which is operated as a regulatory requirement for the dismantlers and recyclers to report their recycled materials and weight data (see Fig. 4). Such reporting systems can be found in other countries like Taiwan. ${ }^{9}$ However, the system does not encompass all recyclers on the ELV recycling routes, and the reported data cannot be confirmed due to incompleteness. For example, the scheme does not include recyclers other than authorized dismantlers, shredders, and ASR operators. This usually leads to a loss of recycling data for the parts collected by unauthorized out-of-network recyclers. Also, information on the separated parts and materials at a dismantling plant may be incorrect or lost, because the data gathering process relies solely on manual

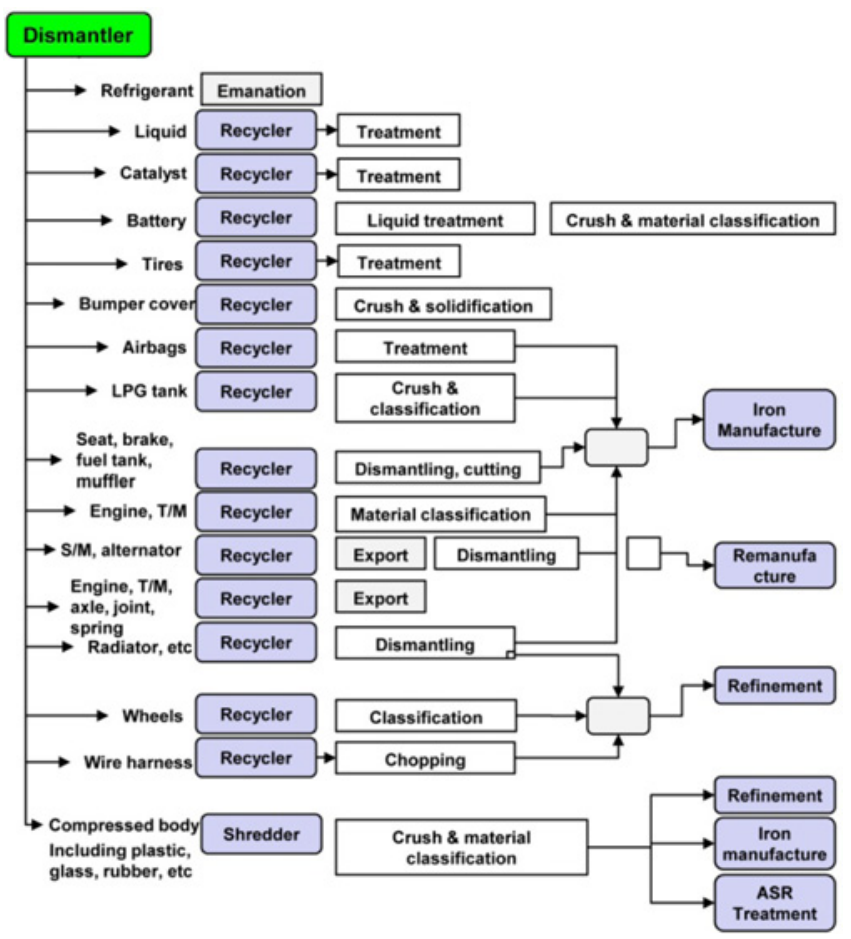

Fig. 2 Sample recycling process

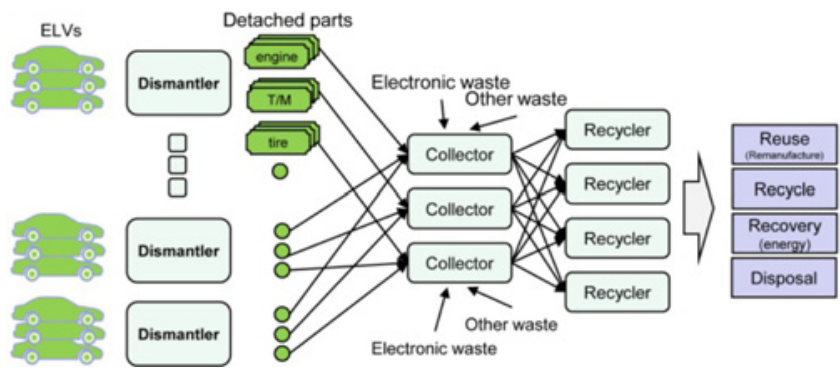

Fig. 3 Complicated recycled material flow 
description. Therefore, it is difficult to collect accurate recycling data in the EcoAS, and a new monitoring system is required.

A design is needed for a systematic reporting \& monitoring system that can trace the flow of parts and materials from dismantling to final treatment (e.g., part reuse, material recycle, energy recovery), in order to facilitate the accurate calculation of recycling rates for the dismantled ELVs. The purposes of such a system are as follows:

Dismantling data collection at the dismantling plant

Recycling data collection from the secondary recyclers

Calculation and estimation of recycling rate based on the recycled weight data

Generation of reports for the EcoAS system interface
To satisfy the requirements, the following information is necessary:

Waste vehicle part lists with weight and material constituents before dismantling

Part separation data at the dismantling plant

Part transfer data

Part treatment type (e.g., reuse, recycle, disposal) and weight

Considering these specifications, a network-based monitoring system should be designed with data gathering and storage tools to facilitate on-line reporting for the authorized operators. In addition, the system has to properly estimate unauthorized operators' recycling data (e.g., loss of recycling data), for which a practical strategy utilizing standard recycling rate (SRR) data is designed in this research.

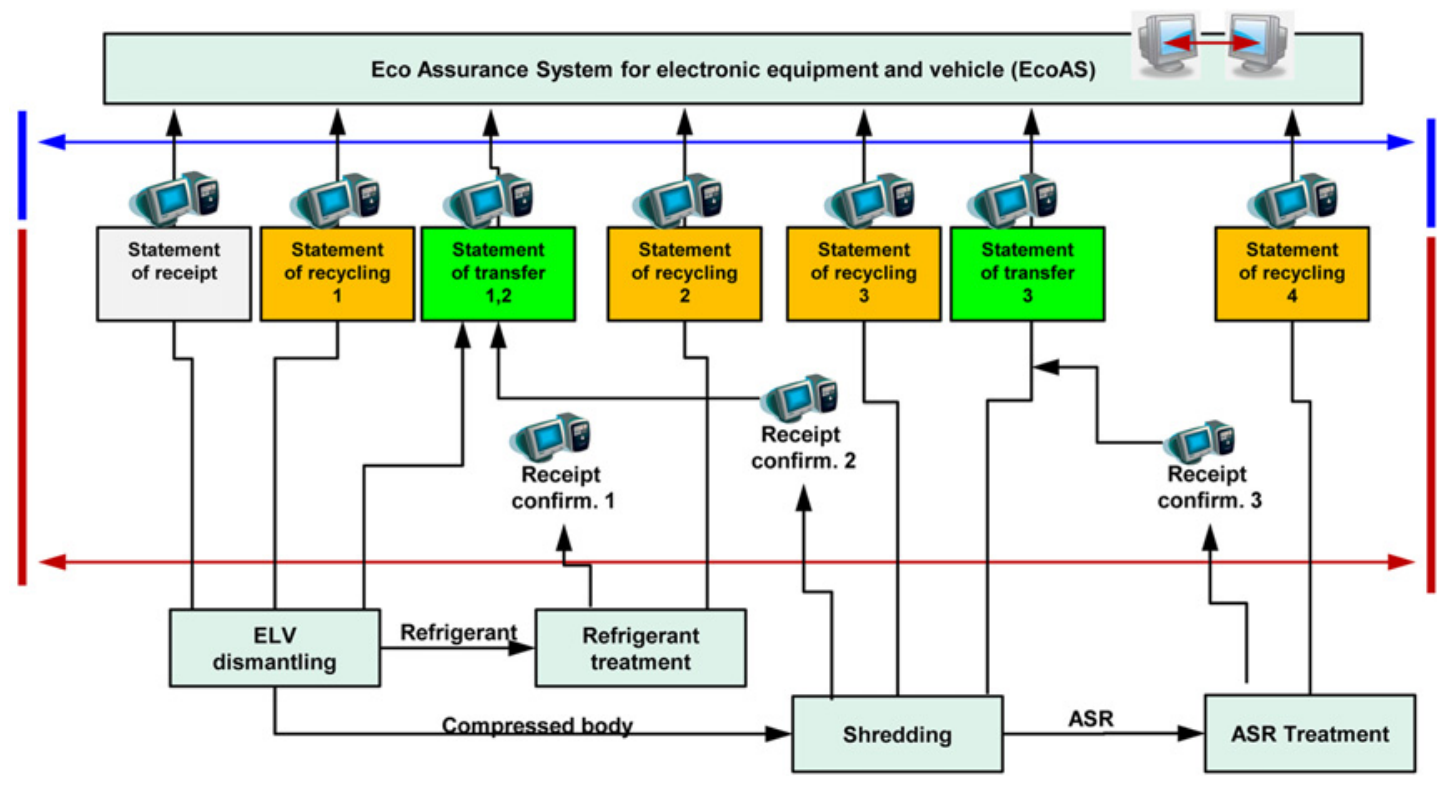

Fig. 4 Overview of EcoAS reporting system

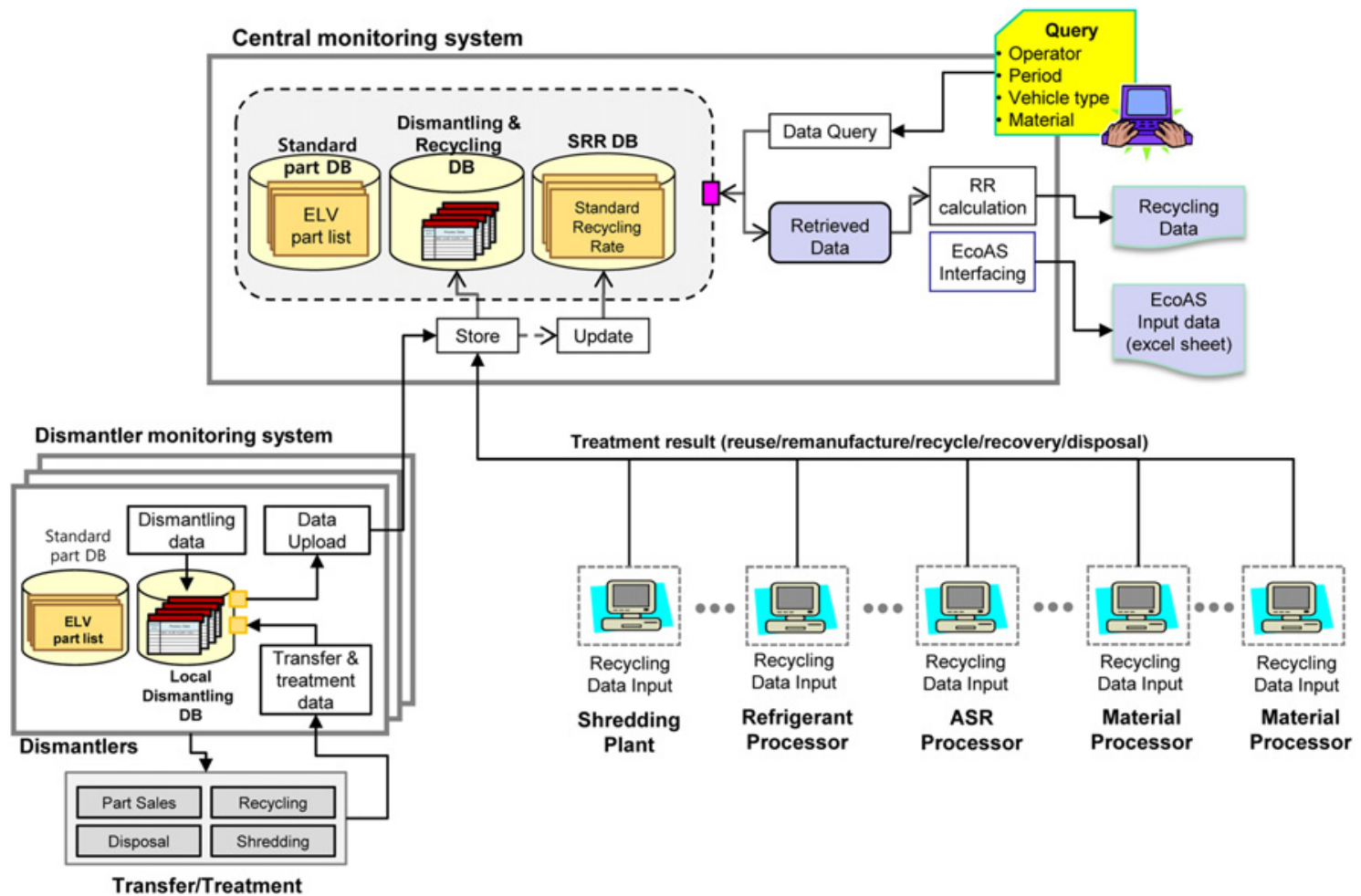

Fig. 5 Schematic diagram of the overall monitoring system 


\section{Monitoring System}

\subsection{Overall View}

The proposed system architecture is a web-based monitoring system equipped with a central database for data gathering and storage. A schematic diagram is shown in Fig. 5. The system is composed of a central monitoring system and a dismantler monitoring system. The dismantler monitoring system locally collects and uploads dismantling data to the database of the central monitoring system (see Fig. 6). Also, the part transfer and treatment data are uploaded. The standard part database provides an initial parts list of each vehicle type, which serves as a basis for creating a dismantling worksheet. All authorized operators in the recycling process can access the system and report their recycling results via the network or over the Internet. The recycling rate (RR) for a certain query is calculated based on the collected data. The system operation is described in Section 3.3 in more detail.

The SRR database is designed as a practical methodology for a reasonable estimation of missed recycling data. Section 3.2 describes how to construct and utilize the SRR database.

\subsection{SRR Database}

The SRR database provides a practical tool to estimate the untraceable part's recycled weight $(\mathrm{RW})$ and recycling rate (RR). Basically, the dismantled parts' recycling result can be obtained through reporting by recyclers. However, the recycling data may not be reported, even when much time has elapsed after dismantling. Presently, there are unauthorized collectors and recyclers who are not obliged to report recycling data. Also, failure to report can even happen with authorized operators (e.g., in the vent that the dismantled parts are not treated yet after some designated time period). To

Dismantler monitoring system

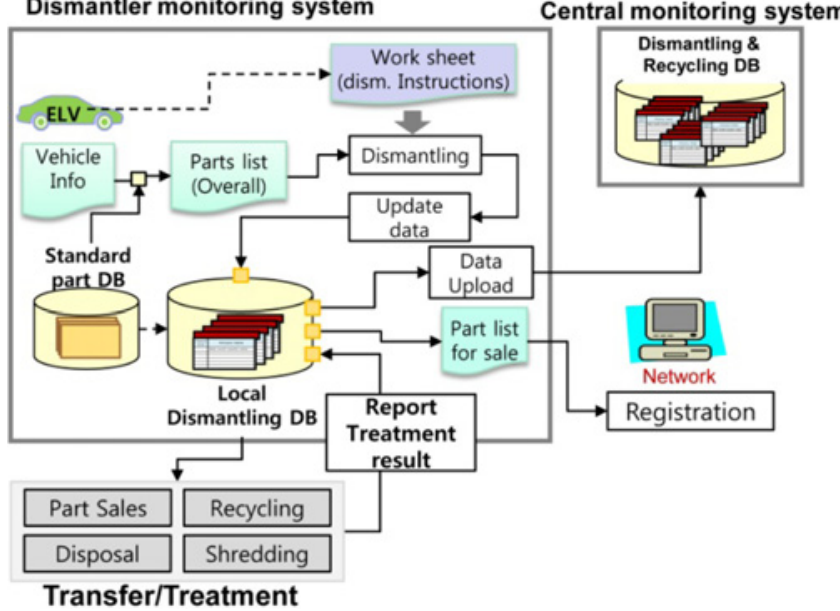

Fig. 6 Schematic diagram of the dismantler monitoring system

\begin{tabular}{|c|c|c|}
\hline Treatment type & $\begin{array}{c}\text { Standard } \\
\text { Recycling Rate } \\
(\%)\end{array}$ & $\begin{array}{c}\text { Respective ratio of } \\
\text { treatment types } \\
(\%)\end{array}$ \\
\hline Reuse & $\mathrm{Ra}$ & $\mathrm{Sa}$ \\
\hline Remanufacturing & $\mathrm{Rb}$ & $\mathrm{Sb}$ \\
\hline Recycle & $\mathrm{Rc}$ & $\mathrm{Sc}$ \\
\hline Recovery & $\mathrm{Rd}$ & $\mathrm{Sd}$ \\
\hline Disposal & $\mathrm{Re}$ & $\mathrm{Se}$ \\
\hline Etc & $\mathrm{Rf}$ & $\mathrm{Sf}$ \\
\hline
\end{tabular}

Fig. 7 Factors for standard recycling rate estimation for a part address this, a 'scenario-based' RR estimation method is proposed.

The construction and utilization of the SRR database is based on an idea that the RR value per dismantled part depends on recycling methods. In other words, the RR value of a part varies according to how it is treated: reuse $(R a)$, remanufacture $(R b)$, material recycle $(R c)$, energy recovery $(R d)$, disposal $(R e)$, etc. $(R f)$. A plastic bumper, for example, may be reused or remanufactured $(R a=R b=100)$, processed and recycled as a resource material for new plastic parts $(R c=80)$, incinerated for energy recovery $(R d=20)$, or sent to a landfill $(R e=0)$. If it is sold for reuse, then its RR is $R a$. Note that the numerical values of $R a$ through $R e$ for each part of an ELV type are estimated based on the current representative recycling method, and may vary as a result.

It is also considered that the selected treatment method for a dismantled part may vary (i.e. between reuse, recycling, recovery, etc.), which leads to RR variation for a dismantled part. A set of the respective ratio values of treatment methods for a part are adopted to estimate the standard recycling rate: reuse $(S a)$, remanufacture $(S b)$, material recycle $(S c)$, energy recovery $(S d)$, disposal $(S e)$, etc. $(S f)$. An average ratio at which a dismantled part is treated is considered. To determine the ratio values, the treatment ratio values from the input data of authorized recyclers are collected and averaged, starting from certain initial values obtained based on field surveys of representative recyclers (see Fig. 8).

A dismantled part's recycled weight $W r$, whose original weight is $W x$, can be estimated as follows: $W r=W x(S a \cdot R a+\ldots+S f \cdot R f)$.

\subsection{Information Flow and Implementation}

\subsubsection{Information flow}

The overall information flow of the proposed system is depicted in Fig. 9, which is summarized as follows. Fig. 10 shows a schematic of

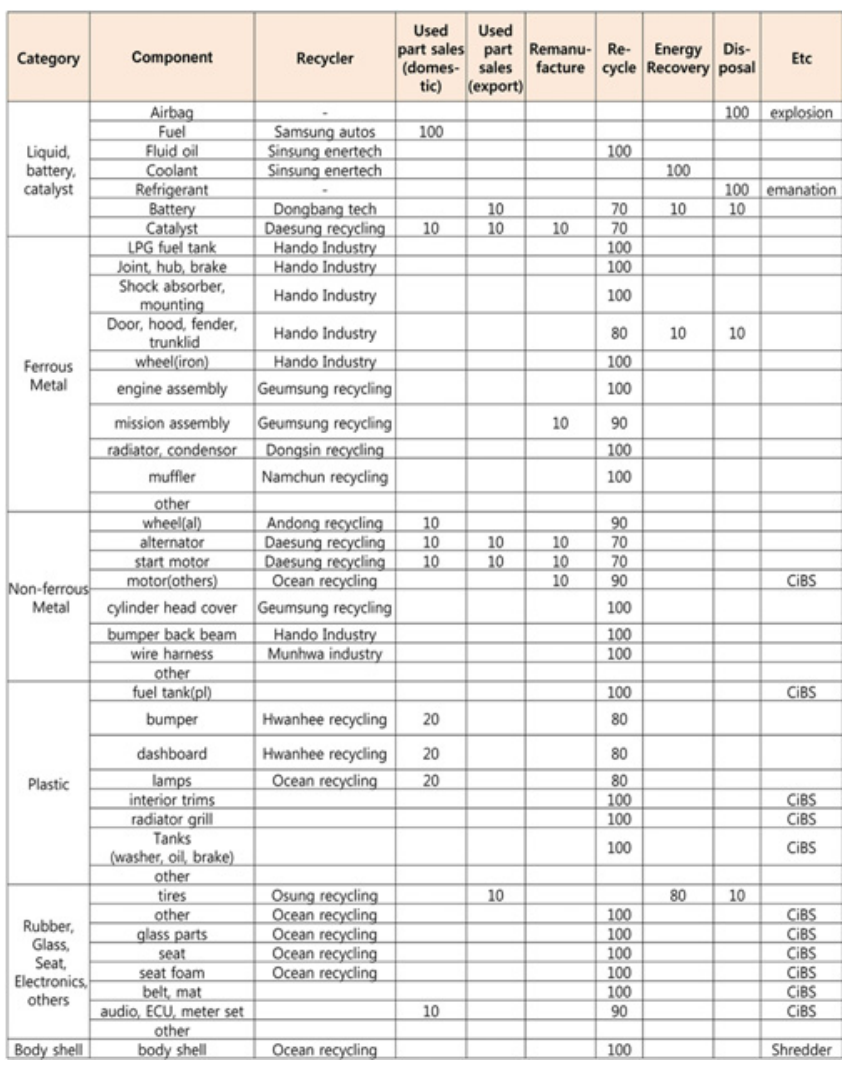

Fig. 8 Sample field survey: respective ratio of treatment 
user interaction, and each number corresponds to those in Fig 9.

[1] Dismantling stage (by dismantler)

A. Dismantling worksheet based on standard part list of the input ELV is created, by which workers follow the separation instructions.

B. Dismantling data (i.e., separation) are stored in the local dismantling database

[2] Upload dismantling data to DR (dismantling \& recycling) database.

[3] Report part transfer data (by dismantler).
A. Dismantled parts transfer to a recycler.

B. Report transfer data (date, recycler, parts).

[4] Update transfer data at the DR database.

[5] Take over dismantled parts \& confirm (by recycler).

[6] Treatment stage (by recycler)

[7] Report processing result (by recycler)

A. Web-based log-in

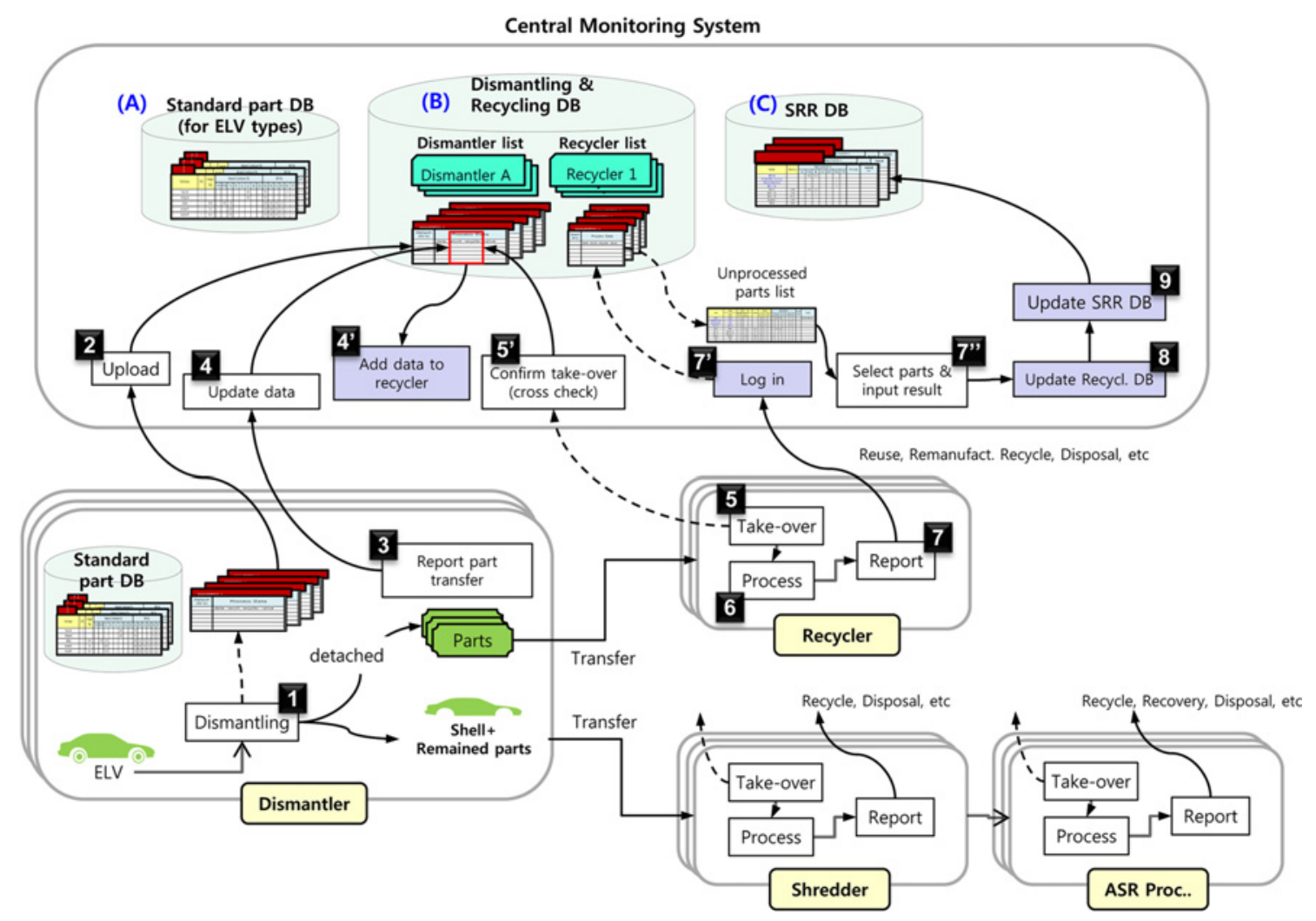

Fig. 9 Information flow of the proposed system
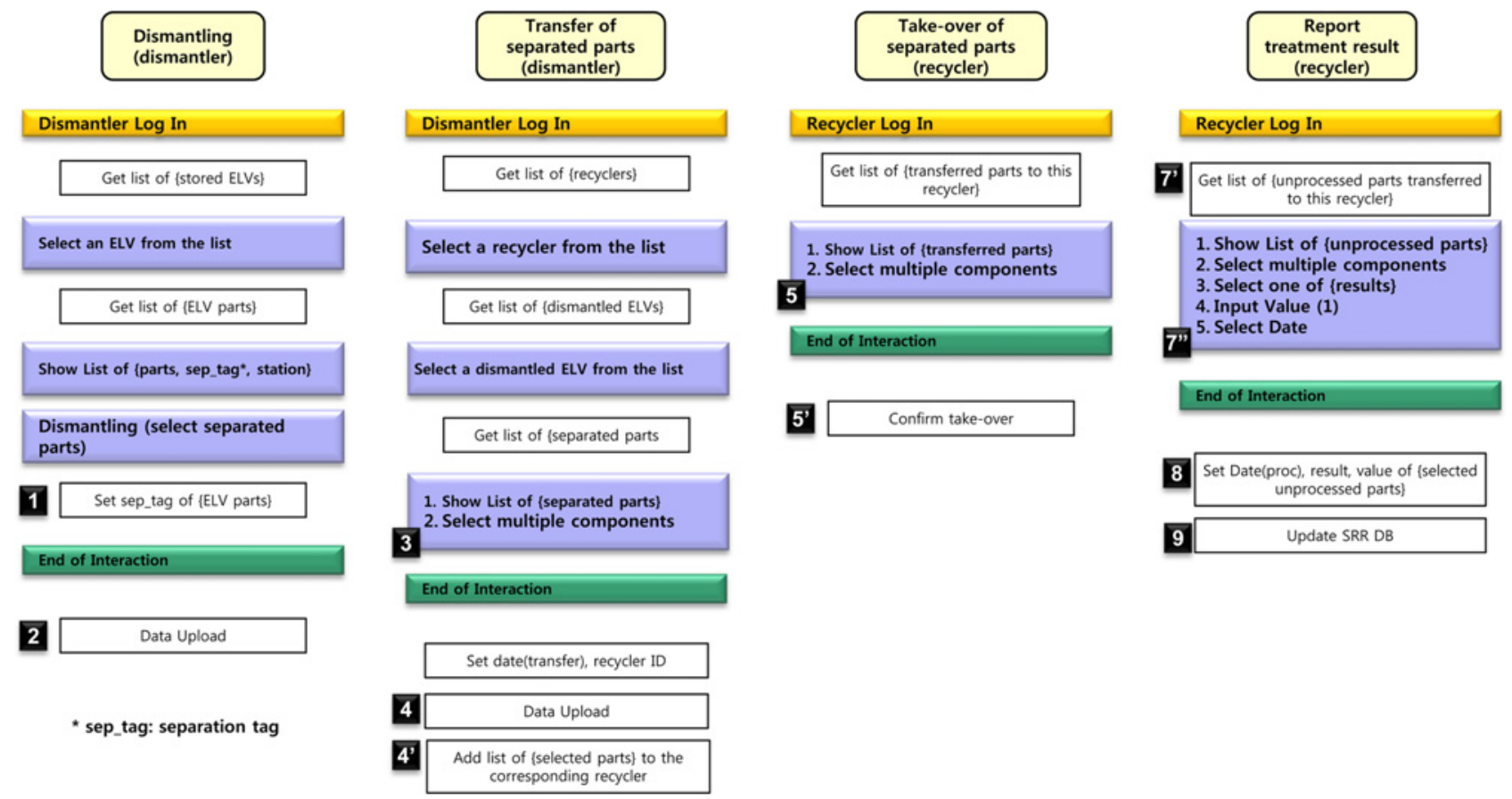

Fig. 10 Schematic user interaction diagrams 
B. Retrieve unprocessed parts list from the DS database.

C. Input treatment type and weight data.

[8] Update recycling data at the DR database.

[9] Update respective ratio data at the SRR database.

\subsubsection{Implementation and Operational Issues}

The proposed system contains three databases: (A) a Standard part database, (B) a Dismantling \& recycling database, and (C) an SRR database. The database design and operation are described as follows.

A vehicle's standard part list for the dismantling process is stored in the standard part database. Each part in the list is a separation unit, and the average number of parts for an ELV is 130. The part list tables for over one hundred vehicle types have been constructed by a Korean automotive recycling company through dismantling operations. Each item of part data of the list includes the part name, weight, MCR (material constituent rate), SRR (standard recycling rate), and RRT

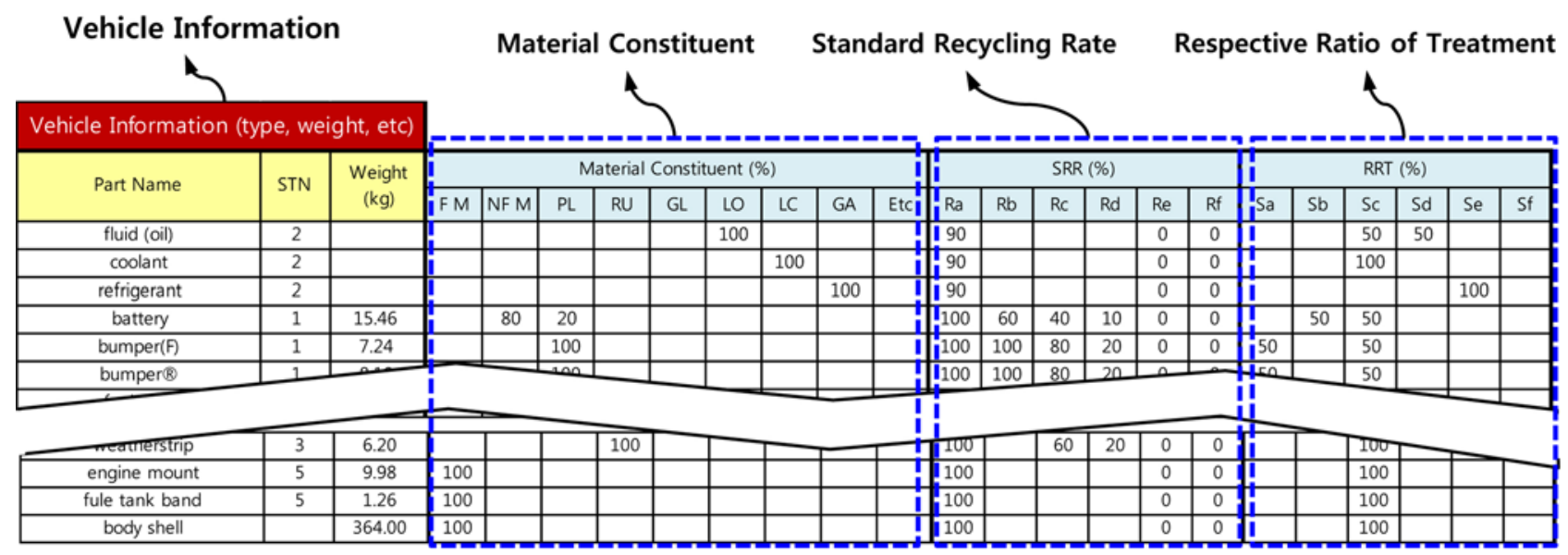

Fig. 11 Example standard part list of an ELV type

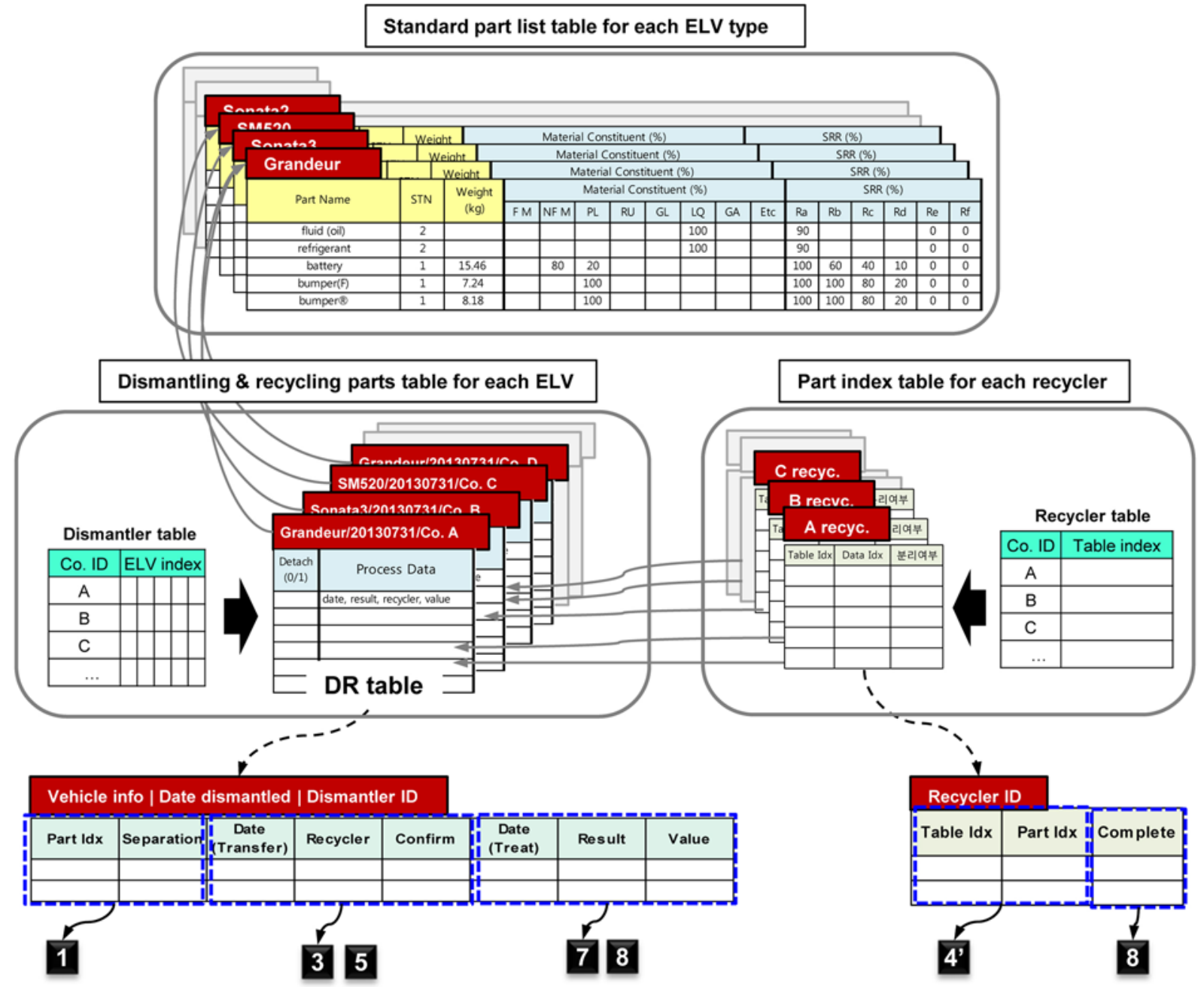

Fig. 12 Data processing of dismantling \& recycling 
(respective ratio of treatment types), as shown in Fig. 11.

The material constituents denote the respective ratios of component materials: ferrous metal (FM), non-ferrous metal (NFM), plastic (PL), rubber (RU), glass (GL), oil (LO), coolant (LC), and refrigerant (GA). This information is used in the estimation of treated material weight for a recycled part. The SRR and RRT data are utilized when estimating the recycling rate of unreported parts, as mentioned earlier.

The dismantling $\&$ recycling database (DS DB) data structure and schematic data processing are shown in Fig. 12, where the numbers denote those in Fig. 9. If an ELV is dismantled at a dismantler, a dismantling \& recycling (DR) parts table for the ELV is instantiated in the dismantler's local server. In the figure, the DR table contains part index ('Part Idx'), part separation ('Separation'), and other recycling data. 'Part Idx' stores the part index of the corresponding standard part list, and 'Separation' denotes whether the part is separated or not. The ELV parts that are not separated in the DR table are supposed to be compressed in the vehicle shell, which is transferred to a shredder. The dismantler's DR table for an ELV is later uploaded into the central dismantling \& recycling database, where the dismantler table stores the loaded DR table index value. The dismantler table contains multiple dismantlers and their own processing ELV data.

When a recycler takes over the separated parts from a dismantler, data fields concerning part transfer are filled: 'Date (transfer),' 'Recycler,' and 'Confirm.' 'Confirm' is set by the accepting recycler's interaction. At the same time, a part index table for each recycler is instantiated, and transferred part indices are stored in the table. When a recycler's part index table already exists, the part data are added to the table.

Finally, the recycling data fields are filled when the recycler finishes treating the transferred parts. The recycler selects one of the treatment types (reuse, remanufacture, recycle, recovery, disposal, etc.) to set 'Result,' and 'Value' is set to 1 (initial value $=0$ ).

\section{Calculation of Recycling Rate}

\subsection{Definition of Recycling Rate}

Guidelines have been established for the calculation of the ELV recycling rate (RR). The Directive 2000/53/EC ${ }^{2}$ and Commission Decision 2005/293/EC ${ }^{3}$ from the EU developed rules for the monitoring of the reuse, recovery, and recycling of ELVs. Also, ISO $22628^{26}$ provides a calculation method of ELV recyclability and recoverability. The recycled weight may be specified at each stage (e.g., pre-treatment, dismantling, shredding, ARS treatment). The basic recycling rate for a given time period is calculated as follows:

$$
R R=\text { Recycled weight / Total vehicle weight } .
$$

The recycled weight (RW) comes from the sum of weights of automobile parts that are reused, recycled, or subjected to energy recovery. ${ }^{3,26}$ The total vehicle weight is the sum of the individual vehicle weights. Weights are defined at recycling stages as shown in Fig. 13, and the recycled weight can be written as follows:

$$
\begin{aligned}
\text { Recycled weight }= & S W_{1 k}+W_{21}+W_{31}+S W_{4 k}+S W_{5 k}+W_{501}(k>0) \\
& \text { Total vehicle weight }=W_{0}
\end{aligned}
$$

The recycled weight at each recycling stage is as follows:

- Weight at reuse stage: $S W_{1 k}$

- Weight at material recycling stage:

$$
W_{21}+W_{31}+S W_{4 k}+S W_{5 k}+S W_{50 k}+W_{501}
$$

- Weight at energy recovery stage: $W_{502}$

The material constituent information of each part facilitates acquisition of the recycled weight of distinct material types (e.g., ferrous metal, non-ferrous metal, plastic, etc.).

\subsection{Calculation of Recycling Rate}

RW (recycled weight) plays an important role in calculating RR, which is acquired from collected data in the central monitoring database. Unless reported, RW is estimated based on the dismantled part's SRR and RRT data as described in Section 3.2. The part's recycled weight $W$, whose original weight is $W_{x}$, is estimated by:

$$
W=W_{x}\left(S a_{x} \cdot R a_{x}+\ldots+S f_{x} \cdot R f_{x}\right)
$$

This estimation method can also be applied to a dismantled part when its treatment is not reported within a designated amount of time. Optionally, the part may be considered to have been discarded. RRT data are continuously updated by recyclers' input, which enhances the fidelity of the calculation. Fig. 14 depicts the RR calculation strategy.

\section{Conclusion and Discussion}

A web-based ELV recycling monitoring system has been designed, and its architecture was described. The monitoring system features

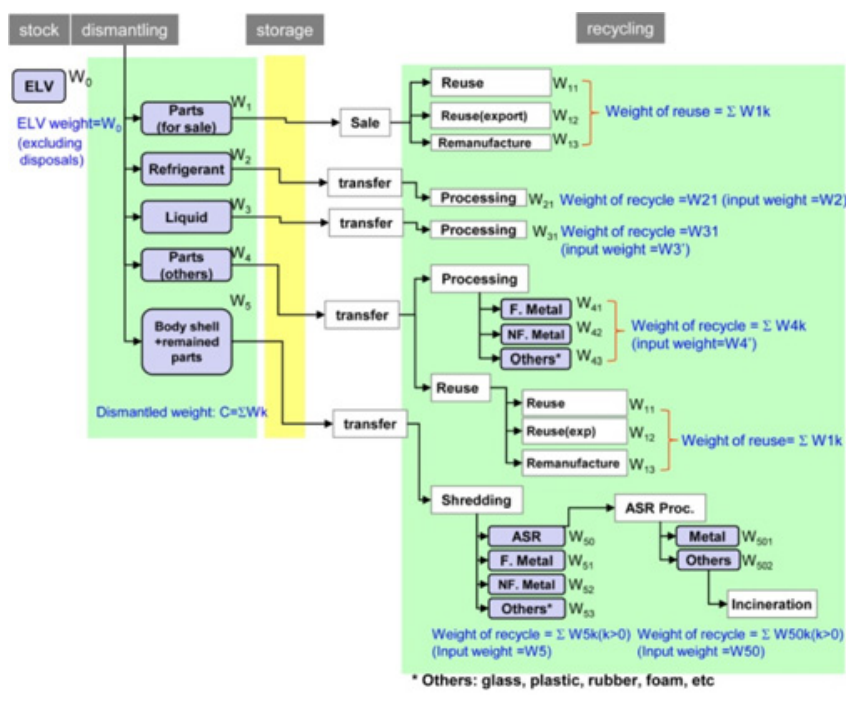

Fig. 13 Weight definition

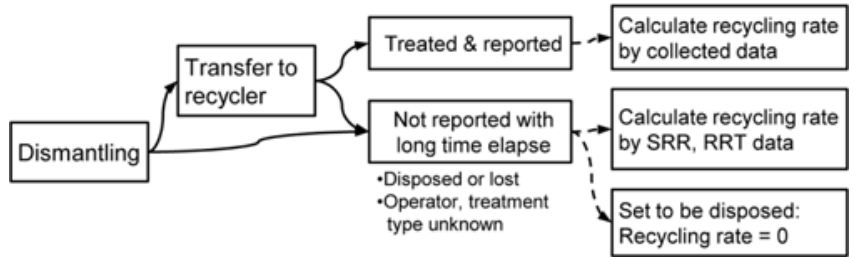

Fig. 14 RR calculation strategy 
three databases: a standard part database, dismantling \& recycling database, and standard recycling rate database. The standard part database provides an ELV part list, which is used to create a dismantling worksheet, as well as for separated part indexing. The dismantling \& recycling database collects all necessary data concerning dismantling, part transfer, and recycling. The standard recycling rate database plays a key role in calculating the practical recycling rate, and features SRR (standard recycling rate) and RRT (recycling ratio of treatment) data for each ELV part. This database facilitates estimation of a reasonable recycling rate for the parts that are unreported within a designated amount of time.

The designed system provides a practical and effective tool for purposes of ELV treatment monitoring, for assisting efficient dismantling, tracing dismantled part usage, collecting recycling data, and calculating and estimating the recycling rate. This reporting \& monitoring system could be better than the present official system in operation in terms of credibility and practicality. The system is currently being implemented in a Windows ${ }^{\circledR}$ environment, and is scheduled to operate for the authorized operators in Korea.

Finally, the applicability of the proposed system should be addressed from two different aspects: system construction and system operation. The monitoring system can be constructed by implementing the database system which collects dismantling \& recycling data, and web-based data input application for the participating authorized treatment actors. The standard part database along with MCR, SRR and RRT data for each ELV could be evaluated by respective dismantling process, field survey and continual update. For a vehicle type for which such data are not existent, the data for a representative vehicle type can be used. The most important problem in operating the proposed system may be fidelity of data gathering, because considerable operators or collectors are involved in from dismantling to ASR treatment stages. It could be overcome by systematic and strategic ways. The legislatively authorized treatment facilities or operators utilize the proposed system, where transfer and receipt of dismantled parts are cross-checked by the system. Also a practical approach to calculation of recycling rate is provided based on SRR and RRT data. It is expected to minimize the discrepancy between calculated and real recycling rate.

\section{ACKNOWLEDGEMENT}

This study was supported by the R\&D Center for Valuable Recycling (Global-Top Environmental Technology Development Program) funded by the Korean Ministry of Environment. (Project No.: GT-11-C-01-160-0, GT-11-C-01-150-0)

\section{REFERENCES}

1. The Korean Institute of Resources Recycling, "The present and future of automotive recycling," Korea Science \& Technology Center, 2012.

2. European Parliament and the European Council, "Directive 2000/53/ EC of the European Parliament and of the Council of 18 September 2000 on end-of life vehicles - Commission Statements," 2000.
3. European Parliament and the European Council, "COMMISSION DECISION of 1 April 2005 laying down detailed rules on the monitoring of the reuse/recovery and reuse/recycling targets set out in Directive 2000/53/EC of the European Parliament and of the Council on end-of-life vehicles (2005/293/EC)," 2005.

4. Korean Ministry of Environment, "Act on resources recycling of electric \& electronic equipment and vehicle 2012.2,” 2012.

5. Santini, A., Morselli, L., Passarini, F., Vassura, I., Carlo, SD., and Bonino, F., "End-of-Life Vehicles Management: Italian Material and Energy Recovery Efficiency," Waste Management, Vol. 31, No. 3, pp. 489-494, 2011.

6. Krikke, H., Blan, I., Krieken, M., and Fleuren, H., "Low-Frequency Collection of Materials Disassembled from End-Of-Life Vehicles on the Value of On-Line Monitoring in Optimizing Route Planning," International Journal of Production Economics, Vol. 111, No. 2, pp. 209-228, 2008.

7. Bluem, T. and Walther, M., "The End-of-life Vehicle Ordinance in the German automotive industry - Corporate Sense Making Illustrated," Journal of Cleaner Production, Vol. 56, pp. 29-38, 2013.

8. Smink C, "Vehicle Recycling Regulations: Lessons from Denmark," Journal of Cleaner Production, Vol. 15, No. 11-12, pp. 1135-1146, 2007.

9. Cheng, Y. W., Cheng, J. H., Wu, C. L., and Lin, C. H., "Operational Characteristics and Performance Evaluation of the ELV Recycling Industry in Taiwan," Resources, Conservation and Recycling, Vol. 65, pp. 29-35, 2012.

10. Che, J., Yu, J. S., and Kevin, R. S., "End-of-life Vehicle Recycling and international Cooperation between Japan, China and Korea: Present and future Scenario Analysis," Journal of Environmental Sciences, Vol. 23, Supplement, pp. S162-S166, 2011.

11. Go, T. F., Wahab, D. A., Rahman, M. N. A., Ramli, R., and Azhari, C. H., "Disassemblability of End-of-Life Vehicle: a Critical Review of Evaluation Methods," Journal of Cleaner Production, Vol. 19, No. 13, pp. 1536-1546, 2011.

12. Park, H. S. and Choi, H. W., "Disassembly Process Planning of End-of-Life Car,” Int. J. Precis. Eng. Manuf., Vol. 6, No. 1, pp. 4250, 2005.

13. Ciacci, L., Morselli, L., Passarini, F., Santini, A., and Vassura, I., “A Comparison among Different Automotive Shredder Residue Treatment Processes," The International Journal of Life Cycle Assessment, Vol. 15, No. 9, pp. 896-906, 2010.

14. Zorpas, A. A. and Inglezakis, V. J., "Automotive Industry Challenges in Meeting EU 2015 Environmental Standard," Technology in Society, Vol. 34, No. 1, pp. 55-83, 2012.

15. Vermeulen, I., Van Caneghem, J., Block, C., Baeyens, J., and Vandecasteele, C., "Automotive Shredder Residue (ASR): Reviewing Its Production from End-of-life Vehicles (ELVs) and Its Recycling, Energy or Chemicals' Valorisation," Journal of Hazardous Materials, Vol. 190, No. 1-3, pp. 8-27, 2011. 
16. Morselli, L., Santini, A., Passarini, F., and Vassura, I., "Automotive Shredder Residue (ASR) characterization for a Valuable Management," Waste Management, Vol. 30, No. 11, pp. 2228-2234, 2010.

17. WF-RepTool , "Documents," http://wf-reptool.org.html (Accessed 23 Dec. 2013)

18. WEEE (Waste Electrical and Electronic Equipment) Forum, "Reporting of WEEE treatment results," http://www.weeeforum.org.html (Accessed 23 Dec. 2013)

19. Eco Assurance System for electronic equipment and vehicle(EcoAS), "User instruction," http://ecoas.or.kr.html (Accessed 23 Dec. 2013)

20. Korea Automotive Recyclers Association, "Research on effective recycling of ELV dismantled parts,” 2009.

21. Chen, K. C., Huang, S. H., and Lian, I. W., "The Development and Prospects of the End-Of-Life Vehicle Recycling System in Taiwan," Waste Management, Vol. 30, No. 8-9, pp. 1661-1669, 2010.

22. Boon, J. E., Isaacs, J. A., and Gupta, S. M., "End-of-Life Infrastructure Economics for "Clean Vehicles" in the United States," Journal of Industrial Ecology, Vol. 7, No. 1, pp. 25-45, 2003.

23. Williams, J. A. S., Wongweragiat, S., Qu, X., McGlinch, J. B., Bonawi-tan, W., and et al., "An Automotive Bulk Recycling Planning Model," European Journal of Operational Research, Vol. 177, No. 2, pp. 969-981, 2007.

24. Qu, X. and Williams, J. A. S., "An Analytical Model for Reverse Automotive Production Planning and Pricing," European Journal of Operational Research, Vol. 190, No. 3, pp. 756-767, 2008.

25. Bandivadekar, A. P., Kumar, V., Gunter, K. L., and Sutherland, J. W., "A Model for Material Flows and Economic Exchanges Within the U.S. Automotive Life Cycle Chain," Journal of Manufacturing Systems, Vol. 23, No. 1, pp. 22-29, 2004.

26. ISO No. 22628 "Road Vehicles - Recyclability and Recoverability Calculation method," 2002. 